\title{
TWO CASES OF GRANULOMATOSIS WITH POLYANGIITIS POST- CORONAVIRUS DISEASE-19 (COVID-19) INFECTION: A RELEVANT VIRAL TRIGGER?
}

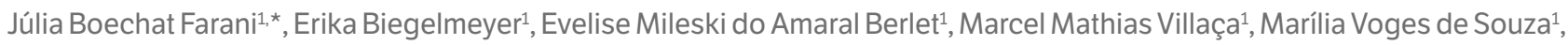
Mauro Waldemar Keiserman ${ }^{1}$, Cristina Ferreira Rabelo ${ }^{1}$

1.Pontifícia Universidade Católica do Rio Grande do Sul, Porto Alegre (RS), Brazil.

*Corresponding author: juliaboechat@globo.com

\section{BACKGROUND}

Inflammatory cytokine release following coronavirus (COVID-19) infection is possibly linked to the development of autoimmune diseases, including granulomatosis with polyangiitis (GPA).

\section{CASE REPORTS}

A 50-year-old, previously healthy white male patient, presented to our hospital with a two-week history of chest pain, dry cough, and progressive dyspnea. Upon admission, there was tachypnea, oxygen desaturation, fever up to $38^{\circ} \mathrm{C}$, myalgia, polyarthralgia of hands, knees and ankles, epistaxis, and a tongue ulcer. Six weeks earlier, he had mild COVID-19 infection confirmed by reverse transcription polymerase chain reaction (RT-PCR). Laboratory workup revealed hemoglobin ( $\mathrm{Hb}$ ) of $11.1 \mathrm{~g} / \mathrm{dL}, 17,970$ leukocytes/ $\mathrm{LL}$, erythrocyte sedimentation rate (ESR) of $98 \mathrm{~mm} / \mathrm{h}$, C-reactive protein (CRP) of $39 \mathrm{mg} / \mathrm{dL}$, hematuria, and mild proteinuria. Rheumatoid factor (RF), antinuclear antibodies (ANA), blood and urine cultures were negative. Chest computed tomography (CT) showed multiple nodular lesions and ground-glass areas, highly suggestive of diffuse alveolar hemorrhage. Within a week, pulmonary function worsened despite high-flow oxygen supply and broad-spectrum antibiotics; Hb levels dropped to $8.4 \mathrm{~g} / \mathrm{dL}$ and creatinine increased up to $2.0 \mathrm{mg} / \mathrm{dL}$. He was admitted to the intensive care unit (ICU) and received noninvasive ventilation. Bronchoscopy and biopsies were precluded by acute respiratory distress syndrome (ARDS). Intravenous pulse therapy with methylprednisolone (MP) was started for five days, followed by $1,000 \mathrm{mg}$ of cyclophosphamide. There was no need for orotracheal intubation as he progressively recovered. Finally, serologies revealed elevated C-antineutrophil cytoplasmic antibodies (C-ANCA) of 1:160 and a positive anti-proteinase-3 antibody (anti-PR3) of $177 \mathrm{U} / \mathrm{mL}$, leading to the diagnosis of GPA. He was discharged with $1 \mathrm{mg} / \mathrm{kg} /$ day prednisone and monthly cyclophosphamide with a favorable outcome. Intriguingly, few months later, a 33-year-old white male patient with obesity and hypertension was also admitted to our ICU due to pulmonary-renal syndrome. There was a similar history of confirmed oligosymptomatic COVID-19 infection 3 months earlier, followed by persistent headache, epistaxis, rhinorrhea, dyspnea, and ARDS requiring mechanical ventilation. The RT-PCR for COVID-19 was negative at admission; chest and sinus CT revealed bilateral ground-glass opacities and extensive consolidations suggesting alveolar hemorrhage, sinusitis and otomastoiditis. There was $\mathrm{Hb}$ of $9.6 \mathrm{~g} / \mathrm{dL}, 17,420$ leukocytes $/ \mu \mathrm{L}$, ESR of $60 \mathrm{~mm} / \mathrm{h}$, CRP of $21 \mathrm{mg} / \mathrm{dL}$, creatinine of 2.1 and mild hematuria. Antinuclear antibodies, RF, ANCA or anti-PR3 were negative. He also received broad-spectrum antibiotics and intravenous pulse therapy with MP for three days, followed by cyclophosphamide, with good recovery.

\section{CONCLUSION}

These are two interesting cases of GPA after COVID-19 infection, adding to the increase in the literature on post-COVID autoimmune manifestations.

\section{KEYWORDS}

Granulomatosis with polyangiitis, COVID-19, Viral trigger. 